\title{
Fabrication of mesoporous carbons coated monolith via evaporative induced self- assembly approach: effect of solvent and acid concentration on pore architecture
}

\begin{abstract}
Carbon coating onto monolith through soft-template approach have been accomplished by means of evaporative induced self-assembly (EISA). Variation in acid and alcohol content on monolith's surface properties was studied, while 6 -carotene was used as a modelled adsorbate. The pore architecture of adsorbent samples was analysed through corresponding surface chemistry, N2 sorption isotherm, pore size distribution (PSD) plot, Brunauerï Emmettï Teller (BET), Barettï Joynerï Halenda (BJH) model and scanning electron microscopy (SEM). SEM images displayed a well-covered interconnected worm-like framework of carbonaceous materials over monolith surface. Surface chemistry studies revealed dominance of acid functionalities over adsorbent samples surface, while basic functionalities remain unaltered. Carbon loading increased with increase in acid concentration, while it decreased with increase in alcohol content. The adsorbent surface area decreased with increase in acid concentration and alcohol content. The 6-carotene adsorption capacities on synthesized samples varied between 179.60 (optimum) and $112.56 \mathrm{mg} / \mathrm{g}$ (lower), respectively. Optimum 6-carotene adsorption was observed on samples MC0.2 and MC5 with alcohol and acid content of $5 \mathrm{~mL}$ and $0.2 \mathrm{~mL}$, respectively.
\end{abstract}

Keyword: Soft-template; Evaporative induced self-assembly; Mesoporous carbon coated monolith; Adsorption; b-Carotene 